\title{
Desinstitucionalização e serviços residenciais terapêuticos: novas perspectivas para o campo da reabilitação psicossocial
}

\author{
Deinstitutionalization and therapeutic residential \\ services: new perspectives on psychosocial \\ rehabilitation's field
}

Elisabete Ferreira Mângia ${ }^{1}$, Ana Lucia Marinho Marques²

\begin{abstract}
MÂNGIA, E. F.; MARQUES, A. L. M. Desinstitucionalização e serviços residenciais terapêuticos: novas perspectivas para o campo da reabilitação psicossocial. Rev. Ter. Ocup. Univ. São Paulo, v. 15, n. 3, p. 129-35, set./dez., 2004.

RESUMO: Este artigo discute a importância que adquire, no contexto do processo de desinstitucionalização de pessoas que viveram longo percurso de internação psiquiátrica, a construção do "habitar", entendido como processo complexo de apropriação e resignificação das formas de viver o cotidiano e aumento do poder contratual, capaz de permitir a participação ativa das pessoas na organização material ou simbólica do lugar onde de vive, assim como a divisão afetiva com outros. Para tanto recorre aos autores da desinstitucionalização italiana e, especialmente às contribuições da experiência de Trieste. No Brasil, o processo de reforma psiquiátrica apresenta resultados significativos na redução de leitos e hospitais psiquiátricos e evidencia que a construção de redes de serviços de saúde mental implica, dentre outros aspectos, na busca de alternativas habitacionais para os egressos de longas internações e para os que ainda vivem em manicômios. Nessa perspectiva, a implementação de serviços residenciais, validada pelo Sistema Único de Saúde a partir do ano 2000, representa um desafio fundamental para o sucesso da Política de Saúde Mental. Assim, buscamos contribuir para a formulação teórica do problema e para a construção de novos entendimentos e significados para os processos de reabilitação psicossocial formulados e desenvolvidos pelos profissionais de saúde mental que atuam em serviços substitutivos.
\end{abstract}

DESCRITORES: Serviços de Saúde Mental. Desinstitucionalização. Instituições residenciais/ tendências. Moradias assistidas/tendências. Apoio social.

${ }^{1}$ Prof ${ }^{\text {a }}$. Dra. do Curso de Terapia Ocupacional do Departamento de Fisioterapia, Fonoaudiologia e Terapia Ocupacional da FMUSP 2 Aluna do Curso de Terapia Ocupacional da Faculdade de Medicina da Universidade de São Paulo.

Endereço para correspondência: Departamento de Fisioterapia, Fonoaudiologia e Terapia Ocupacional da Faculdade de Medicina da Universidade de São Paulo. Rua Cipotânea, 51. Cidade Universitária - CEP: 05360-000 - São Paulo, SP. 
$\mathrm{O}$ contexto pós-guerras viu crescer a sensibilidade e a crítica em relação à situação dos hospitais psiquiátricos. $\mathrm{O}$ movimento de crítica a essas instituições, denominadas por Goffman (2003) de "Instituições Totais" e por Basaglia (2001) de "Instituições da Violência" e ao modelo hegemônico de atenção psiquiátrica centrada na institucionalização permanente das pessoas com transtornos mentais severos, foi impulsionado a partir dos anos 1950 e décadas posteriores (BARROS, 1994). Dessa forma, há mais de quatro décadas, muitos países passaram a modificar suas práticas assistenciais no campo da psiquiatria, preocupando-se com a criação de políticas de saúde mental voltadas para o desenvolvimento de novas formas de cuidado (MÂNGIA; ROSA, 2002; BARROS, 1994).

No Brasil, o movimento que se convencionou denominar Reforma Psiquiátrica constituiu-se a partir do final dos anos 1970 e deve ser entendido como um processo contínuo de construção de reflexões e transformações que engloba e articula os campos técnicoassistencial, político-jurídico, teórico-conceitual e sócio-cultural (AMARANTE, 1997; AMARANTE et al., 1998). Partindo da lógica da desinstitucionalização, foram propostas novas formas de tratamento e serviços que, mais que "alternativos" ou "paralelos" ao hospital psiquiátrico, deveriam configurar-se como substitutivos. Atualmente, fazem parte da nova rede de cuidados no campo da atenção psicossocial os Centros e Núcleos de Atenção Psicossocial (CAPS e NAPS), HospitaisDia, Centros de Convivência e Cooperativa, Serviços Residenciais Terapêuticos, dentre outros (ROTELLI et al., 2001; MÂNGIA; NICÁCIO, 2001).

Tendo como cenário a tendência de reversão do modelo hospitalar, encontra-se, entre os vários desafios presentes na atualidade, a necessidade de aumentar os recursos orçamentários para a Saúde Mental e consolidar e ampliar a rede de atenção de base comunitária e territorial. No Brasil, se avalia que $12 \%$ da população necessita de algum atendimento, contínuo ou eventual, em saúde mental e que apenas 2,3\% do orçamento anual do SUS tem sido dirigido a essa área, o que se caracteriza como insuficiente diante da dimensão do problema ${ }^{1}$. Estudos europeus, publicados em 1998, estimaram que em países como a Holanda e Reino Unido, os gastos com transtornos mentais, proporcionalmente aos gastos com todos os serviços de saúde foram de $23,2 \%$ e $22 \%$, respectivamente
(Inverso'; OMS/OPAS, 2001).

Considerando-se o panorama mundial, pode-se perceber que os serviços residenciais têm obtido destaque, no contexto da realização dos projetos de desinstitucionalização e na implementação das Reformas Psiquiátricas (WHO, 1993; OMS/OPAS, 2001; MÂNGIA; ROSA, 2002). Os serviços residenciais podem responder às diversas demandas no percurso do fechamento dos hospitais psiquiátricos e implementação de processos assistenciais baseados na comunidade e no resgate de cidadania: local para morar, suporte social, composição de rede social e responsabilização diferenciada de serviços e equipes de saúde mental (MÂNGIA; ROSA, 2002).

Os serviços residenciais mostram-se especialmente importantes para a população internada há longo tempo nos hospitais psiquiátricos: isolada, freqüentemente sem qualquer contato social e/ou familiar, e sem possuir vínculos com seu território de origem (MÂNGIA; ROSA, 2002). Os serviços residenciais, vinculados a serviços de atenção psicossocial, são instrumentos fundamentais para a superação do modelo ainda hegemônico, centrado na internação hospitalar. Sem eles, o processo de saída do hospital poderia resultar no abandono daqueles que não possuem suporte social e/ou familiar (VASCONCELOS, 2001).

No Brasil, no final dos anos $1980 \mathrm{e}$, principalmente, na década de 1990, no contexto da construção do Sistema Único de Saúde - SUS - alguns municípios passaram a se responsabilizar pela construção de novas políticas em saúde mental que convergissem para a transformação do modelo assistencial, a implementação de uma rede de atenção e a garantia e construção de direitos para as pessoas com transtornos mentais (MÂNGIA; NICÁCIO, 2001).

Na década de 1990, no estado de São Paulo, foram desenvolvidos os primeiros serviços residenciais nos municípios de Campinas, Ribeirão Preto, Santos e São Paulo antes mesmo do estabelecimento da normatização específica por parte do SUS (MÂNGIA; ROSA, 2002).

Com a Portaria/GM n ${ }^{\circ} 106$, de 11 de fevereiro de 2000 e Portaria $\mathrm{n}^{\circ} 1220$, de 7 de novembro de 2000, os serviços residenciais em saúde mental foram regulamentados e definidos como:

“(...) moradias ou casas inseridas, preferencialmente, na comunidade, destinadas a cuidar dos portadores de transtornos mentais, egressos de internações psiquiátricas de longa permanência

\footnotetext{
${ }^{1}$ Fonte: Coordenação Geral de Saúde Mental.

${ }^{2}$ Endereço eletrônico no qual estão disponíveis acessos a bancos de dados e informações em geral. Disponível em: http:// www.inverso.org.br
} 
que não possuam suporte social e laços familiares e, que viabilizem sua inserção social" (BRASIL, 2002).

Atualmente, além da priorização dada aos egressos de longas internações, considera-se que possam ser também beneficiários os egressos de internação em Hospital de Custódia e Tratamento Psiquiátrico, pessoas em acompanhamento nos Centros de Atenção Psicossocial (CAPS), quando o problema da moradia for avaliado como fundamental ao desenvolvimento de projeto terapêutico condizente com as suas necessidades; e finalmente, indivíduos em situação de rua com transtornos mentais severos, quando inseridos em projetos terapêuticos especiais, acompanhados nos CAPS (BRASIL, 2004).

Muitas experiências têm sido impulsionadas em todo o país e a vivência cotidiana demonstra a possibilidade de responder aos desafios colocados pela desinstitucionalização de acordo com as condições sócio-culturais de cada região. No estado de São Paulo existiam, em julho de 2004, 134 residências credenciadas ao SUS, contemplando um total de 653 moradores ${ }^{3}$.

Nesse contexto, é preciso criatividade, flexibilidade e disponibilidade (KINOSHITA, 1997) das equipes técnicas, para imaginar e planejar suportes residenciais os mais diversificados possíveis, de acordo com as necessidades de seus usuários. Saraceno (2000) aponta para a necessidade da construção de um olhar atento à descoberta e potencialização dos recursos tradicionalmente desconsiderados pelos serviços: a comunidade, os equipamentos públicos e privados, os usuários e suas famílias são todos recursos a serem acionados, de acordo com a demanda de cada caso a ser acompanhado.

\section{Desinstitucionalização e os novos sentidos da reabilitação}

Para a elaboração de nossos questionamentos e reflexões, optamos pela orientação teórica dos autores da desinstitucionalização italiana. O movimento de desinstitucionalização, iniciado há cerca de quatro décadas, em muitos países, foi impulsionado pela idéia de renovar a capacidade terapêutica da psiquiatria, questionando suas funções de coação, segregação e controle social. A origem do termo está ligada às práticas desenvolvidas nos EUA, e designava o processo de alta e reinserção na comunidade dos pacientes psiquiátricos. Contudo, na sociedade européia pós-guerras, surgiram movimentos de transformação da assistência psiquiátrica, que produziram diversos desdobramentos e significados para a noção de desinstitucionalização (BARROS, 1990, 1994; ROTELLI et al., 2001).

Duas posições distintas disputam a hegemonia no campo da saúde mental: o modelo da segregação e internação e o da intervenção na comunidade. Para esta última, apresentam-se duas estratégias de desinstitucionalização e enfrentamento do manicômio: a reorientação do modelo assistencial, com a criação de serviços na comunidade que convivem com a internação psiquiátrica e a posição que defende a necessidade de desconstrução do manicômio e reconversão total dos recursos nele investidos (BARROS, 1990).

Ao optar por esta última posição, a experiência italiana de desinstitucionalização propôs que o confronto e o trabalho de desmontagem do manicômio deveria se dar a partir do interior da instituição, subvertendo sua lógica e o seu funcionamento, e utilizando-se "dos recursos e dos problemas internos da estrutura em decomposição para construir, pedaço por pedaço, as novas estruturas externas" (ROTELLI et al., 2001, p. 35).

Para tal transformação, mostrava-se necessário o envolvimento e protagonismo de todos os sujeitos envolvidos na desmontagem da solução existente e na invenção e produção de novas possibilidades de pensar e agir. Esse modo de operar "não apenas desconstruiu, mas também construiu: tornou a instituição um terreno produtivo de inovações e fez de seus recursos e de seus atores, recursos e atores da produção do novo" (DE LEONARDIS ${ }^{4}$ apud NICÁCIO, 2003).

Na transformação da condição da pessoa internada, do mandato social e da função exercida por técnicos e instituição, adotaram-se como estratégias: a garantia do direito de proteção e alojamento a quem necessitasse, a construção de espaços reais de trabalho, a instalação de estruturas residenciais na cidade, a utilização de subsídios como recurso para promoção de autonomia, e "a vida grupal como necessidade de todos" (BARROS, 1994).

Nesse processo de desconstrução, emergiu uma nova figura, o "hóspede", para designar o estatuto jurídico-administrativo dos indivíduos que permaneceram no manicômio, não por uma razão médica, mas pelo reconhecimento de sua necessidade de proteção e alojamento. Assim, o estatuto de hóspede,

\footnotetext{
${ }^{3}$ dados fornecidos pela Coordenação Geral de Saúde Mental.

${ }^{4}$ DE LEONARDIS,O. II terzo escluso: le istituzioni come vincoli e come risorse. Milano: Feltrinelli, 1990. p.68.
} 
representava a denúncia da incapacidade da cidade em acolher e oferecer condições de vida adequadas às pessoas. (BARROS, 1994). Os "hóspedes" usam o hospital "como uma casa", tendo assegurado o direito de entrar e sair voluntariamente. Mas, de fato,

“o manicômio não é uma casa: a 'hospitalidade' representa de modo claro que se vai ou se está no manicômio por falta de alternativas de casas, de dinheiro, de relações e de apoio, de recursos para viver e para se reconhecer no tecido das trocas sociais" (DE LEONARDIS et al., 2001, p. 72).

A emergência dessa contraditória figura exigiu a superação da tutela institucional e a construção de uma relação contratual, a partir do reconhecimento do "hóspede" enquanto um sujeito de direitos e deveres e portador de necessidades. Uma nova modalidade de trabalho foi forjada, a partir do momento em que os técnicos, despojados de poder sobre o paciente e vendo-se agora diante de um cidadão, deveriam construir novos caminhos que potencializassem essa relação (BARROS, 1994).

Nesse percurso, também, era fundamental transformar as barreiras entre o dentro e fora dos muros do manicômio. Tornava-se necessário uma profunda transformação sócio-cultural, a fim de que a população passasse a tolerar a convivência com a diversidade; realizar a "desconstrução simbólica" do manicômio (BARROS, 1994). Buscava-se, assim, a promoção de lugares de encontro e intercâmbio.

Nesse sentido, os técnicos, ou operadores de saúde mental, desempenhavam um papel fundamental na mediação dos conflitos com a cidade. Nessa mediação, o exercício do estar com deveria ser constante, problematizando, mostrando as contradições, auxiliando e dando voz aos sujeitos, potencializando a experimentação de si e da relação com o outro (BARROS, 1994).

É fundamental apreender que, desde o inicio, o trabalho de desinstitucionalização voltava-se a tentar recompor o universo simbólico dos indivíduos, partindo de suas necessidades reais e concretas (BARROS, 1994). As mudanças simples, porém significativas, produzidas a partir do interior do manicômio - eliminação dos mecanismos de contenção, coação, tutela jurídica e do estatuto de periculosidade; a restituição e reconstrução dos direitos civis, do uso do tempo, espaço, objetos pessoais e da relação com o próprio corpo; a reconstrução do direito e uso da palavra, a produção de relações, espaços e objetos de interlocução e intercâmbio - situam a desinstitucionalização enquanto um trabalho terapêutico, voltado para a reconstituição das pessoas enquanto sujeitos que sofrem (ROTELLI et al., 2001).

Nesse percurso, a ênfase é dada no projeto de "invenção de saúde" e "reprodução social do paciente", o que delineia a descoberta de que cuidar significa ocupar-se da transformação dos modos de viver e sentir o sofrimento dos sujeitos, e que, ao mesmo tempo, se transforme sua vida concreta e cotidiana (ROTELLI et al., 2001). Esse será o caminho a ser trilhado pelas novas proposições no campo e na construção de novas práticas reabilitativas.

\section{Os territórios das trocas e a importância do habitar}

No trabalho de negação e desconstrução do manicômio e construção de efetivas possibilidades de produção de vida, que assegurem a transformação das relações, saberes e práticas no campo da saúde mental, é importante entender a lógica das relações que mantém essa instituição.

O manicômioé o "lugar zero da troca". Compartilhar dessa premissa significa entender que a única finalidade da tutela e da internação é estabelecer relações de mera dependência pessoal, que "zeram e objetivam" o indivíduo de forma a impossibilitá-lo de participar da rede de trocas sociais (ROTELLI, 2001). Para evidenciar o que acontece ao indivíduo submetido ao controle institucional, Basaglia (2001) utilizou-se da seguinte imagem:

"Uma fábula oriental conta a história de um homem em cuja boca, enquanto ele dormia, entrou uma serpente. A serpente chegou ao seu estômago, onde se alojou e de onde passou a impor ao homem a sua vontade, privando-o assim da liberdade. O homem estava à mercê da serpente: já não se pertencia. Até que uma manhã o homem sente que a serpente havia partido e que era livre de novo. Então dá-se conta de que não sabe o que fazer da sua liberdade: "No longo período de domínio absoluto da serpente, ele se habituara de tal maneira a submeter à vontade dela a sua vontade, aos desejos dela os seus desejos e aos impulsos dela os seus impulsos, que havia perdido a capacidade de desejar, de tender para qualquer coisa e de agir autonomamente". "Em vez de liberdade ele encontrara o vazio", porque "junto com a serpente saíra a sua nova 'essência', adquirida no cativeiro", e não lhe restava mais do que reconquistar pouco a pouco o antigo conteúdo humano de sua vida" (p. 132). 
Goffman (2003) evidencia que as Instituições Totais, que compreendem os hospitais psiquiátricos, têm por objetivo explícito a normalização. A arquitetura, a separação entre os sexos, os regulamentos, o rígido controle do tempo, a ruptura com os laços sóciofamiliares, concretizam a exigência da manutenção da ordem e da disciplina. No hospital, todas as dimensões da vida acontecem no mesmo lugar, rigorosamente organizadas segundo um ritmo preestabelecido e reguladas por uma única autoridade.

Para Basaglia apud Saraceno (1999, p.62), o poder institucionalizante que caracteriza e articula a vida do asilo, leva o indivíduo internado a "objetivar-se nas próprias regras que o determinam, em um processo de aparvalhamento e de restrição de si que originariamente sobreposto à doença - não é sempre reversivel".

Nessa perspectiva, se deve considerar que a desinstitucionalização requer um investimento especial nos sujeitos. Para Saraceno (2000), o processo chave no trabalho de fechamento dos manicômios é o da "reconstrução histórica dos internos, a reapropriação de seu passado e presente, a reapropriação do sentido que cada um deles produziu em sua vida". Uma primeira etapa nesse percurso é o reconhecimento de que todo indivíduo é dotado de valor e produtor de sentido.

Para entender esse pressuposto, é necessário reconhecer que no universo social, é a partir de uma certa capacidade real ou reconhecida, que entramos (ou não) em relação com o outro. Esse poder contratual é precondição para qualquer processo de intercâmbio, de trocas. Nesse processo, três dimensões são consideradas fundamentais: trocas de bens, de mensagens, e de afetos. No caso da pessoa rotulada como doente mental, seu valor pressuposto é negativo, seu poder de contrato é anulado e qualquer possibilidade de trocas mostra-se impossível, uma vez que: seus bens são considerados suspeitos; suas mensagens, incompreensíveis e seus afetos desnaturados (KINOSHITA, 2001).

O processo de reabilitação deveria, então, configurar-se enquanto processo destinado a reconstruir esses valores, aumentar o poder contratual do sujeito, criar situações que possibilitem a participação no processo de trocas sociais e, em meio a mediações e experimentações, levar à modificação de uma situação de desvalor pressuposto para um valor possível (KINOSHITA, 2001). Para Saraceno (1999, p.112), a reabilitação se constitui como "um conjunto de estratégias orientadas a aumentar as oportunidades de trocas de recursos e de afetos: é somente no interior de tal dinâmica das trocas que se cria um efeito "habilitador".
Nesse sentido podemos afirmar que o processo da reabilitação implica a abertura contínua de "espaços de negociação" para todos os sujeitos envolvidos: paciente, família, comunidade e serviços. A partir do direito ativo ao exercício da negociação, entendida como oportunidades de trocas, o sujeito pode exercitar o direito à relação. A criação e multiplicação das oportunidades de trocas materiais e afetivas, como o tecido de "redes de negociação" articuladas e flexíveis, aumentam a participação e contratualidade real dos sujeitos (SARACENO, 1999).

No processo de construção, reconstrução e aumento da capacidade contratual dos indivíduos, Saraceno (1999, 2001) delineia, de forma esquemática, três grandes cenários nos quais atuamos no dia-a-dia: o habitat, o mercado e o trabalho. Tais cenários, complexos e de difícil definição, são os territórios das trocas e das relações sócio-afetivas, nos quais entramos com maior ou menor poder contratual e constituem os eixos sobre os quais se constrói o aumento da capacidade contratual dos sujeitos (SARACENO, 1999, 2001).

Atentemos para o cenário habitat. No trabalho de desinstitucionalização é necessário encontrar respostas à necessidade de moradia dos indivíduos, que não pode ser traduzida apenas enquanto necessidade de um lugar para estacionar, pois se assim fosse o manicômio bastaria. Nesse processo, Saraceno (1999) traz a importância da diferenciação entre estar e habitar um lugar. Enquanto o estar está relacionado com uma escassa ou, até mesmo, nula apropriação material e simbólica do espaço no qual se vive, o habitar implica em um processo contínuo de apropriação, além de um elevado grau de contratualidade. Enquanto o primeiro representa o não pertencimento e um não poder de decisão, o habitar implica um poder contratual tal que permita a participação ativa na organização material e simbólica do lugar onde de vive, assim como a divisão afetiva com outros.

Compreender esse pressuposto implica em manter separados, na teoria, os conceitos de casa e de habitar. No plano prático, contudo, o trabalho de reabilitação deve estar voltado à construção de respostas a essas duas demandas. É necessário intervir junto ao direito da conquista concreta da casa, assim como de sua aquisição enquanto processo de formação de cidadania do indivíduo. Mas há também a necessidade de um trabalho relacionado à ativação de desejos e habilidades relacionados ao habitar (SARACENO, 1999).

É certamente importante que, no contexto dos processos de reforma psiquiátrica, sejam criadas respostas às distintas demandas e exigências apresentadas pelos sujeitos: casas protegidas, casas 
grupais, casas para um único morador, comunidadesalojamento, grupo-apartamento. Mas, na prática, é necessário também oferecer oportunidades de experiências concretas de reaquisição, reconstrução do uso do espaço, tempo, objetos e oportunidades da vida cotidiana, assim como a possibilidade de revisitar a casa passada, raízes, lugares, memórias e impossibilidades (SARACENO, 1999).

Ao longo de sua história, a psiquiatria se mostrou sempre preocupada em criar espaços, materiais ou simbólicos, que pudessem circunscrever o objeto de seu domínio, sendo insensível à noção de habitar (VENTURINI, 2003). O manicômio, lugar onde são zeradas as trocas, onde a relação estabelecida não é contratual, é portanto, lugar onde o habitar é negado.

Assim, na desconstrução do manicômio e produção de novas possibilidades assistenciais, importa trilhar o caminho inverso: produzir e potencializar relações que ultrapassem as relações de poder, abrir espaços de negociação, aumentar as possibilidades de trocas de recursos e de afetos no interior da dinâmica de trocas sociais, facilitar a criação de redes de pertencimento, transformar as formas de estar no e relacionar-se com o mundo.

A casa pode ser o lugar privilegiado de elaboração de experiências, onde o tempo interior ganha espaço e as relações de objeto, significado. A experiência de viver em uma casa, participar da vida comunitária, pode abrir possibilidades de emancipação, de produção e reprodução de outros papéis (cidadão, portador de direitos, consumidor, produtor...) e de trazer à cena e dar voz a novos protagonistas (VENTURINI, 2003).

Nossas casas certamente podem representar a oportunidade de exercitar o poder e o prazer de habitar, mas mesmo nelas, podemos experimentar a perda de poder contratual e de pertencimento material ou simbólico (SARACENO, 1999). Sendo assim, onde quer que se encontre o sujeito, pode haver a necessidade de um trabalho sobre o habitar, a ser realizado junto, cabendo ao técnico a função de intermediação de ações, relações, recursos e contextos.

Nesse sentido, mostra-se necessária, também, a construção de um olhar atento para os pequenos e sutis acontecimentos que compõem o dia-a-dia das pessoas. Ações que nos parecem banais podem ter um especial significado e produzir sentido na vida dos sujeitos e exigem, assim, um investimento cotidiano e contínuo, estando junto, fazendo com, resgatando percursos, trajetórias e sentidos, despertando desejos, reconstruindo e ressignificando as ações diárias e as muitas sutilezas que tecem a cotidianidade.

MÂNGIA, E. F.; MARQUES, A. L. M. Deinstitutionalization and therapeutic residential services: new perspectives on psychosocial rehabilitation's field. Rev. Ter. Ocup. Univ. São Paulo, v. 15, n. 3, p. 129-35, set./dez., 2004.

\begin{abstract}
This article discusses the importance that construction of "living" acquires in the context of the deinstitutionalization processes of people who had lived a long course of psychiatric hospital admissions. The referable construction can be understood as a complex process that involves appropriation and resignification of ways to live the everyday life and to increase individual's contractual power, that can allow people's active participation in the material and symbolic organization of the place where they live as well as the affectionate division with others. In order to do so, this paper is anchored in the Italian deinstitutionalization process and, specially, in the contributions that the Trieste experience can bring. In Brazil, the Psychiatric Reform process has presented significant results on reduction of hospital beds and psychiatric hospitals. It has also evidenced that the construction of Mental Health services' nets involves, apart from other aspects, the search for housing alternatives to people who come from a long internment process and to those ones who have still lived in asylums. In this perspective, the implementation of residential services, which has been validated by SUS (Unified Health System), starting from the year 2000, represents a fundamental challenge to the success of Mental Health Policy. Therefore, we have been looking for contributing to the theoretical formulations of this problem and to the construction of new understandings and meanings to the psychosocial rehabilitation's processes that have been formulated and developed by mental health professionals who act in substitutive services.
\end{abstract}

KEY WORDS: Mental health service. Deinstitucionalization. Residential facilities/trends. Assisted living facilities/trends. Social support. 


\section{REFERÊNCIAS}

AMARANTE, P. (Coord.). Loucos pela vida: a trajetória da reforma psiquiátrica no Brasil. 2a. ed. Rio de Janeiro: Fiocruz, 1998.

AMARANTE, P. Loucura, cultura e subjetividade: conceitos e estratégias, percursos e atores da reforma psiquiátrica brasileira. In: FLEURY, S. (Org.). Saúde e democracia: a luta do CEBES. São Paulo: Lemos, 1997.

BARROS, D. D. A desinstitucionalização é desospitalização ou desconstrução? Rev. Ter. Ocup. Univ. São Paulo, São Paulo, v. 1, n. 1/2, p. 101-106, 1990.

BARROS, D. D. Jardins de Abel: desconstrução do manicômio de Trieste. São Paulo: EDUSP/Lemos, 1994.

BASAGLIA, F. As instituições da violência. In: BASAGLIA, F. (Coord.). A instituição negada: relato de um hospital psiquiátrico. 3a. ed. Rio de Janeiro: Graal, 2001.

BRASIL. Ministério da Saúde. Legislação em saúde mental, 1990-2002. 3a. ed. Brasília, 2002. (Série E. Legislação de Saúde).

BRASIL. Ministério da Saúde. Secretaria de Atenção à Saúde. Departamento de Ações Programáticas Estratégicas. Residências terapêuticas: o que são, para que servem. Brasília, 2004. (Série F. Comunicação e Educação em Saúde).

GOFFMAN, E. Manicômios, prisões e conventos. 7a. ed. São Paulo: Perspectiva, 2003.

KINOSHITA, R. T. Contratualidade e reabilitação psicossocial. In: PITTA, A. (Org.). Reabilitação psicossocial no Brasil. 2a. ed. São Paulo: Hucitec, 2001.

KINOSHITA, R. T. Em busca da cidadania. In: CAMPOS, F. C. B; HENRIQUES, C. M. P. (Orgs.). Contra a maré à beira-mar: a experiência do SUS em Santos. 2a. ed. São Paulo: Hucitec, 1997

MÂNGIA, E. F.; NICÁCIO, F. Terapia ocupacional em saúde mental: tendências principais e desafios contemporâneos. In: CARLO, M. M. R. P.; BARTALOTTI, C. C. Terapia ocupacional no Brasil: fundamentos e perspectivas. São Paulo: Plexus, 2001.
MÂNGIA, E. F.; ROSA, C. A. Desinstitucionalização e serviços residenciais terapêuticos. Rev. Ter. Ocup. Univ. São Paulo, São Paulo, v. 13, n. 2, p. 71-77, maio/ago. 2002.

NICÁCIO, F. Utopia da realidade: contribuições da desinstitucionalização para a invenção de serviços de saúde mental. 2003. 224 p. Tese (Doutorado) - Universidade Estadual de Campinas, Campinas, 2003.

ORGANIZAÇÃO MUNDIAL DA SAÚDE (OMS), Organização Panamericana da Saúde (OPAS). Relatório sobre a saúde no mundo - 2001. Saúde mental: nova concepção, nova esperança. Gráfica Brasil, Organização Mundial da Saúde, 2001.

ROTELLI, F. O Inventário das Subtrações. In: NICÁCIO, F. (Org.). Desinstitucionalização. 2a. ed. São Paulo: Hucitec, 2001. p. 61-64.

ROTELli, F.; LEONARDIS, O.; MAURI, D. Desinstitucionalização, uma outra via: a reforma psiquiátrica Italiana no contexto da Europa Ocidental e dos "países avançados". In: NICÁCIO, F. (Org.). Desinstitucionalização. 2a. ed. São Paulo: Hucitec, 2001.

SARACENO, B. A Cidadania como forma de tolerância. 2000. S.L.p. (mimeo).

SARACENO, B. Libertando identidades: da reabilitação psicossocial à cidadania possível. Rio de Janeiro: Instituto Franco Basaglia/ Te Corá, 1999.

VASCONCELOS, E. M. Os novos dispositivos residenciais no quadro atual da reorientação da assistência psiquiátrica brasileira. In: BRASIL. Ministério da Saúde. Conselho Nacional de Saúde. Caderno de textos de apoio da III Conferência Nacional de Saúde Mental. Brasília, 2001.

VENTURINI, E. A qualidade do gesto louco na época da apropriação e da globalização. In: AMARANTE, P. Archivos de saúde mental e atenção psicossocial. Rio de Janeiro: Nau Editora, 2003. p. 157-184.

WHO - World Health Organization. Transition from hospital to community: a literature review on housing. Geneva, 1993. (WHO/MNH/MND, 93.17). 